\title{
Determining potential of subcooling to attenuate hydrodynamic instabilities for steam-water two phase flow
}

\author{
Khairuddin Sanaullah a,*, Afrasyab Khan ${ }^{\mathrm{b}, \mathrm{c}}$, Mohd Sobri Takriff ${ }^{\mathrm{d}}$, Hushairi Zen ${ }^{\mathrm{e}}$, Ajmal Shah ${ }^{\mathrm{f}}$, \\ Imran Rafiq Chughtai ${ }^{\mathrm{g}}$, Tahir Jamil ${ }^{\mathrm{h}}$, Lim Soh Fong ${ }^{\mathrm{b}}$, Noaman Ul Haq ${ }^{\mathrm{c}}$

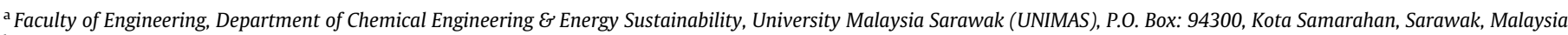

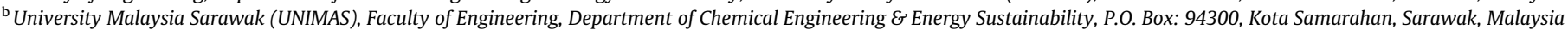 \\ ${ }^{\mathrm{c}}$ National University of Sciences and Technology (NUST), School of Chemical and Materials Engineering (SCME), Department of Chemical Engineering, H-12 Islamabad, Pakistan

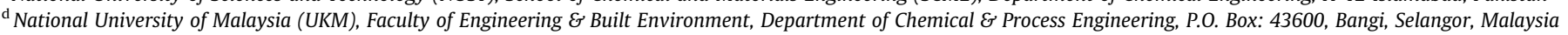 \\ e University Malaysia Sarawak (UNIMAS), Faculty of Engineering, Department of Electronic Engineering, Malaysia \\ ${ }^{\mathrm{f}}$ Pakistan Institute of Engineering \& Applied Sciences (PIEAS), Department of Mechanical Engineering, Nilore, Islamabad, Pakistan \\ ${ }^{g}$ Pakistan Institute of Engineering \& Applied Sciences (PIEAS), Department of Chemical Engineering, Nilore, Islamabad, Pakistan \\ ${ }^{\mathrm{h}}$ Institute of Chemical Engineering \& Technology, Punjab University, Lahore, Pakistan
}

\section{A R T I C L E I N F O}

\section{Article history:}

Received 18 September 2014

Received in revised form 6 December 2014

Accepted 26 December 2014

\section{Keywords:}

Pressure

Hydrodynamic

Instability

Temperature

Steam

Wate

\begin{abstract}
A B S T R A C T
Hydrodynamic instabilities are regarded as important but are undesirable occurrences for the systems used in process industries, which involve steam. These instabilities affect to a great extent the life line of the safe operation of their systems by inducing thermal stresses and steam induced water hammers. On the basis of system operational analysis, it was found that condensation induced hydrodynamic instabilities were responsible for one third of the destructive events in steam driven systems and their attributes in power and process industry. Thus it becomes vital to investigate the influence of critical parameter such as sub-cooling to curb the destructive effects due to hydrodynamic instabilities on to the process equipment. Here for steam water two phase flows, the attenuation of hydrodynamic instabilities due to sub-cooling and inlet pressure has been investigated. It was found that sub-cooling has more pronounced and notable effect on the attenuation of these instabilities.
\end{abstract}

(c) 2015 Elsevier Ltd. All rights reserved.

\section{Introduction}

It is not a story of old gone ages that a need was felt by some of the intuiting minds from the field of engineering and science to investigate the hydrodynamics of the steam water two phase flows. Steam interaction with water is a process that we can observe in myriad industries including nuclear power industries, process intensive heat exchangers and wherever boiler is used by the ever restless process industry. When steam and water comes into contact with each other an interface is formed between them, across which heat, mass and momentum transfer occur. If the steam is injected at high relative speed, it forms a jet. Details of the physical phenomenon active at the interface between steam jet and water and its vicinity depend mainly on the power of spa-

\footnotetext{
* Corresponding author. Tel.: +60 168619960.

E-mail addresses: skhairuddin@feng.unimas.my (K. Sanaullah), 12010046@ siswa.unimas.my, afrasyab@scme.nust.edu.pk (A. Khan), sobri@eng.ukm.my (M.S. Takriff), zhushair@feng.unimas.my (H. Zen), ajmal@pieas.edu.pk (A. Shah), imran@pieas.edu.pk (I.R. Chughtai), tahirj4@yahoo.com (T. Jamil), sflim@feng. unimas.my (L.S. Fong), noaman@scme.nust.edu.pk (N.U. Haq).
}

tial and temporal resolution of the instrument used to monitor the region inside and around the interface. Moreover, it is strenuous to investigate and find information through the steam-water interface due to its strong fluctuating nature and hitherto hidden science on theoretical, computational and to some extent experimental basis.

When steam is injected at low mass flow rate into water at supersonic speed, small scale temperature fluctuations occur, owing mainly to the emergence of Kelvin-Helmholtz hydrodynamic instabilities. In process industry in general and in nuclear power industry in particular when steam at high inlet pressure and high mass flow rate is injected into pressure suppression pool i.e. subcooled water it results into large scale hydrodynamic instabilities that ultimately lead to steam induced water hammers, which brought catastrophic consequences if unable to handle with precautionary safety measures. According to Chun and Yu [1] 34\% of the 283 events, compiled by Van Duyne et al. [2] were due to the condensation induced water hammers. The creation and propagation of hydrodynamic instabilities in case of high pressure and mass flow rate steam injection is an obvious fact which is further 